\title{
On the Relationship between Economic Growth and $\mathrm{CO} 2$ Emissions: The Bangladesh Experience
}

\author{
Janifar Alam ${ }^{1^{*}}$ \\ ${ }^{1}$ University of Information Technology and Sciences, Bangladesh
}

\begin{abstract}
This paper investigate changes in economic structure and trends of carbon dioxide (CO2) emissions with GDP per capita of Bangladesh. The paper also examine the relationship between economic growth (GDP per capita) and CO2 emissions of Bangladesh based on the environmental Kuznets curve hypothesis, using World Bank data over 1972-2010. By estimating the EKC for the period 1972-2010, the existence of EKC " $U$ " shape does not hold. It is also seen that a faster structural shift from agriculture to non-agriculture and emergence of services as the dominant part of the economy so CO2 emissions shows uprising trend.
\end{abstract}

Keywords: Environmental Kuznets Curve, Environmental degradation, Structural change, GDP per capita, Carbon dioxide emissions

\section{Introduction}

Global warming due to climate change has become one of the most important issues in the recent years. $\mathrm{CO} 2$ is considered to be the major contributor to global warming. $\mathrm{CO} 2$ emissions have grown dramatically in the past century because of human activities, mainly by the use of fossil fuels consumption such as coal, oil and gas, the main power of source of electricity generation, manufacturing activities, transport and consumption of goods and services that are directly linked with economic growth. So there is a systematic relationship between economic growth and environmental quality, the relationship known as the Environmental Kuznets Curve (EKC), by analogy with the income-inequality relationship postulated by Kuznets. The EKC is named after Simon Kuznets (1955), who hypothesized that as a country develops, economic inequality increases first, and then decreases after reaching to a certain average income. The EKC hypothesis (1991) stated an inverted Ushape relation between various indicators of environmental quality and per capita income. The theory of Environmental Kuznets Curve reveals that environmental degradation increases at initial level of development and starts to decline as economy achieves high level of economic development. There is evidence of EKC trend for many environmental pollutants such as biological oxygen demand (BOD), Chemical oxygen demand (COD), nitrates, and some heavy metals which are arsenic and cadmium (Yandle et al. 2002). Carbon dioxide (CO2) accounts for the largest portion of greenhouse gas emissions and a major source of environmental problems. The growth of Gross Domestic Product (GDP) is specifically a good indication of economic growth. Thus it is meaningful to examine the causal relationships between $\mathrm{CO} 2$ emissions and GDP per capita where $\mathrm{CO} 2$ is not a local pollutant but global one.

\subsection{Objectives of the Study}

The objectives of this study are:

(a) Changes in Economic Structure and Trends of carbon dioxide (CO2) Emissions with GDP per capita of Bangladesh and

(b) To observe the existence of EKC relationship between $\mathrm{CO} 2$ emissions and economic growth (GDP per capita) of Bangladesh.

\section{Theoretical Background}

It has been argued that EKC is an inverted-U-shaped relationship between economic growth (per capita income) and measured pollution indicators (indicators of environmental quality). In fact EKC hypothesis summarizes a dynamic process of change; as income of an economy grows over time, emission level grows first, reaches a peak and then starts declining after a threshold level of income has been achieved. 


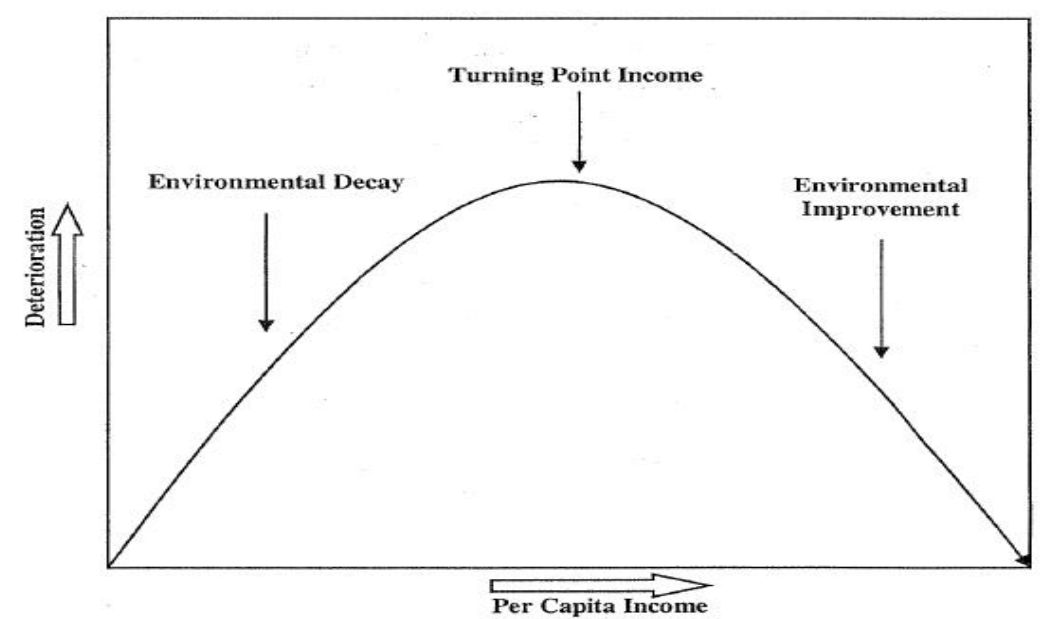

Figure 1: Environmental Kuznets Curve

The relationship between economic growth and $\mathrm{CO} 2$ emissions reveals that, initially economic growth is linked with high $\mathrm{CO} 2$ emissions tends to decrease as an economy attain turning point on threshold level of economic growth.

Environmental Kuznets Curve (EKC) model represents the structural change of economy with economic growth as economic growth is linked to continuous structural transformation and change. Structural changes reflects the changes in the shares of agriculture, industry and services have broadly followed by the same time pattern with the changes in growth rate but the content of change have varied from period to period. By changing the composition of economic activity to the sectors it affects environmental quality with higher or lower pollution intensity.

The first and most common explanation of an inverted-U Kuznets relationship is the stages of economic growth economies go through as they make a transition from agriculture to industry and then post industrial service-based systems. As pointed out by Panayotou (1993, p. 14), environmental degradation tends to increase as the structure of the economy changes from rural to urban and from agricultural to industrial as mass production and consumption grow. It then starts falling with the second structural change from energy-intensive heavy industry to services and technology-intensive industry due to the lower environmental impact of service industries.

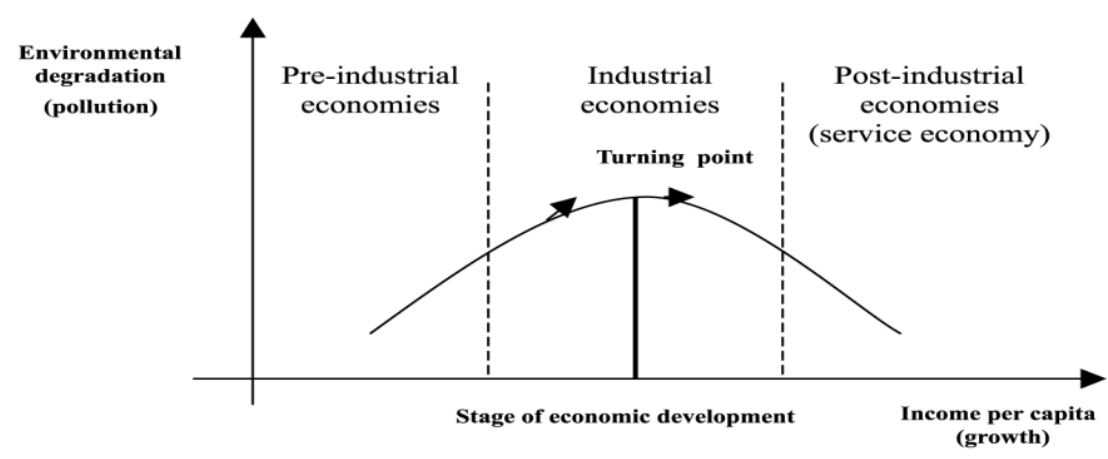

Source: Panayotou (1993)

Figure 2: Stages of Economic Development

At lower levels of income, the dominant shift is from agriculture to industry and pollution intensity increases as waste and pollution generates as mass production and consumption grow in the economy due to greater use of natural resources, more emission of pollutants, emphasize to increase in material output. At higher incomes, economic development progresses, the dominant shift is for industry to post-industrial or service economy as the share of industry will go down as services goes up because of increased environmental awareness, higher environmental expenditures, efficient technologies and increased demand for environmental quality. 


\section{Literature Review}

Much has been written on the growth-environment relationship and on the Environmental Kuznets Curve (EKC). Several literature supports to inverted $U$ shape curve and some literature rejecting inverting $U$ shape.

Akbostanci et al. (2009) investigated the relationship between income and environmental degradation in Turkey. By using a time series model spanning from 1968 to 2003, they found that CO2 emissions and income tend to have a monotonically increasing relationship in the long run. This monotonically increasing relationship implies that the EKC hypothesis does not hold in this case.

Cole et al. (1997) investigated the relationship between GDP per capita and a wide range of indicators by using cross-country panel data and suggested that meaningful EKCs exist only for local pollutants. More global or indirect environmental effects tend to increase monotonically with income, which implies that it is easier to improve urban air pollution than to reduce national air pollution.

Galeotti et al. (2009) explained that EKC is not found at all the times relating to $\mathrm{CO} 2$.

Grossman and Krueger $(1993,1995)$ studied the effect of GDP per capita on various local environmental indicators. For most indicators-sulfur dioxide (SO2) concentrations, suspended particulate matter (SPM), biological oxygen demand, chemical oxygen demand, and arsenic in rivers - an inverted-U shape curve emerges. In particular, the turning point estimates for these pollutants are under $\$ 8,000$ (in 1985 US dollars) of GDP per capita.

Maddison and Rehdanz (2008) find strong evidence for bidirectional causal relationship between per capita GDP and per capita $\mathrm{CO} 2$ emissions except for Asia. In case of Asia, there is no evidence of $\mathrm{CO} 2$ per capita caused by GDP per capita.

Miah et al., (2010) show that EKC for CO2 in Bangladesh follows a monotonous straight line in most cases.

Selden and Song (1994) investigated this relationship for GDP per capita and four air pollutants- SPM, $\mathrm{SO} 2$, oxides of nitrogen (NOx), and carbon monoxide (CO)-which are from the same sources as Grossman and Krueger $(1993,1995)$, and found evidence of a Kuznets curve for all four pollutants but the turning points for $\mathrm{SPM}$ and $\mathrm{SO} 2$ exceed $\$ 8,000$.

\section{Methodology}

Here we apply World Development Indicators (WDI), 2013 and World Bank data to see the trends and patterns of $\mathrm{CO} 2$ emissions (metric tons per capita) according to GDP per capita (current US \$) for the year of 1972 to the year of 2010 for Bangladesh. To concentrate the sector wise GDP change over the decade and years of Bangladesh, we analyze the contribution (\% of Value Added) of three basic economic sectors- Agriculture, Industry and Services we also use World Development Indicators (WDI), 2013 and World Bank data.

\section{Analysis and discussion}

After fighting a devastating independence war with Pakistan, Bangladesh emerged as an independent country in 1971. In terms of land mass, Bangladesh is only the 94th largest country in the world with a surface area of 147,570 square kilometers (56,977 square miles) and the number of population is 166,280,712 (July 2014 est.) Bangladesh has been officially identified by the United Nations (UN) as a least developed country (LDC), reflecting its low income, weak human assets, and high economic vulnerability. It has been striving very hard to move to Middle Income Country (MIC) status. In fact, it has made significant progress in terms of income growth (per capita income rising by $56 \%$ from US\$438 in 2005 to US\$685 in 2009/10). The country has posted an average annual GDP growth rate of about $4.8 \%$ in the 1990 s which improved to over $5 \%$ on average during 2000-2008 and to over 6\% during the past few years. In the year of 2013, Annual GDP growth of Bangladesh was 6.03\% (WDI 2013, World Bank Data).

Bangladesh is also recognized worldwide as one of the most vulnerable countries to the impacts of climate change. Most vulnerable climate change effects of Bangladesh is sea level rise, salinity ingress, storm surges, cyclones, floods, loss of habitat, destabilization of agriculture etc. . The agriculture, mining and manufacturing industries are responsible for large amounts of greenhouse gas emissions. Bangladesh's contribution to global carbon emissions is negligible at per capita/annum emission of 0.3 tonnes compared to the global average of 1.6-2.0 tonnes for the developing countries, and about 20 tonnes in USA.

\subsection{Changes in Economic Structure and Trends of carbon dioxide (CO2) Emissions with GDP per capita of Bangladesh}

The economic growth is stimulated by all sectors of economy including agricultural, industrial and services. The vast population of Bangladesh is directly associated with agriculture with a view to ensuring food security, poverty alleviation, and increased generation of employment. Industry and services sector significantly 
contribute to GDP growth of Bangladesh. Now sector wise GDP change from the year of 1980 to the year of 2012 are graphically (Fig.5.1.1) shown in below.

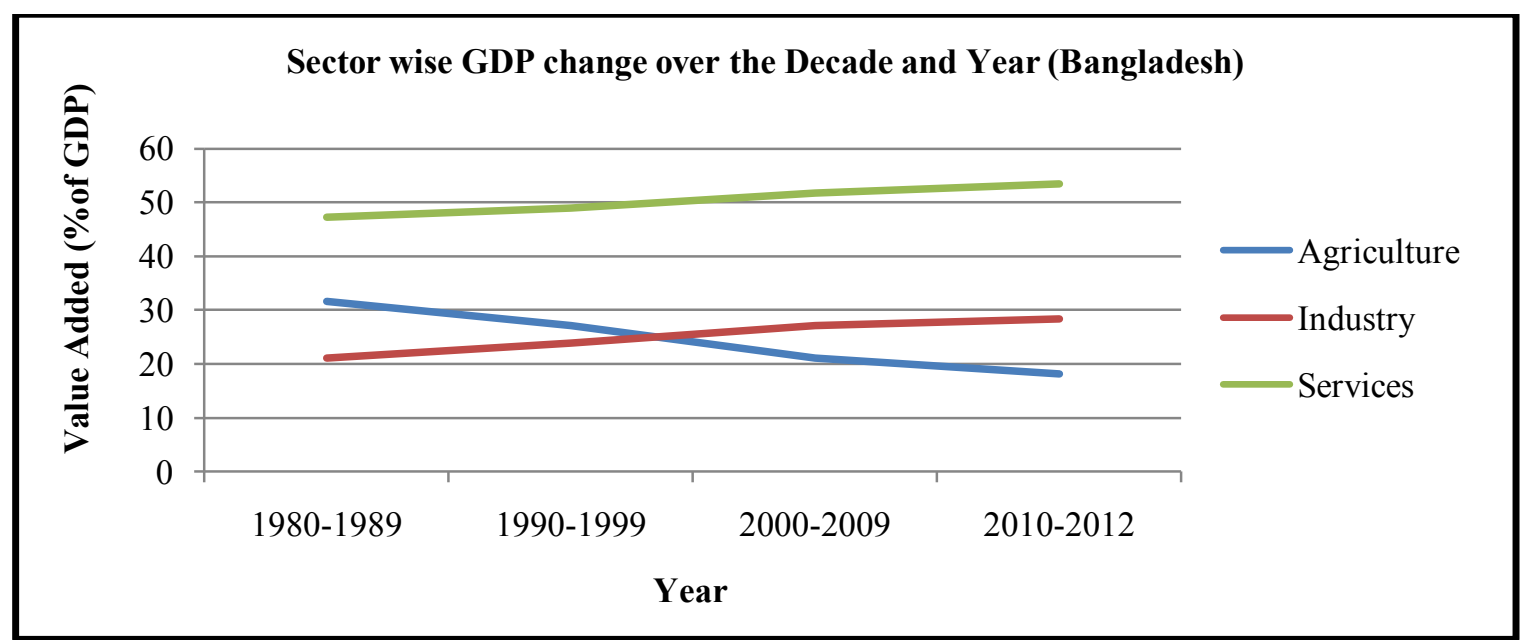

\section{Source: World Development Indicators (2013), World Bank Data \\ Figure 5.1.1: Sector wise GDP contribution over the decade and year in percentage (Bangladesh)}

The above graphical representation of sector wise GDP change over the decade and years of Bangladesh (Fig.5.1.1) shows that the share of agriculture has continued consistently decline over the past three decades: from 31.60 percent in 1980-1989 to 27.14 percent in 1990-1999 to 21.19 percent in 2000-2009, to about 18.18 percent in 2010-2012. Industry and Services have both increased their share, but at different pace and in different periods. Accordingly, their relative contribution to the growth of and importance in GDP has varied over different periods. On the basis of the observed patterns of growth and structural changes, economic growth in post-independence Bangladesh can be divided into the following four phases, each with its distinguishing features.

\section{Phase 1. 1980 to 1989s:}

After independence, this period (1980-1989) shows slower growth of industry sector which yield lower share to GDP which is aggregately 21.17 in percentage that is lower than the contribution of agriculture and services sector. In this decade, agriculture sector reveals higher growth than industry and services sector which is 31.60 in percentage and services sector also shows a high growth of 47.23 in percentage.

\section{Phase 2. 1990 to 1999s:}

The period of 1990-1999 shows a slower growth of GDP, accompanied by a deceleration in the growth of agriculture which stands 27.14 in percentage, a slower pace of structural shift from agriculture to nonagriculture and modest increase in the share of industry and services which is consecutively 23.94 and 48.93 in percentage.

\section{Phase 3. 2000 to 2009s:}

This period (2000-2009) saw a sharp acceleration in growth rate, mainly contributed by services. Structural changes were also swift, with a large decline in the share of agriculture which is 21.19 in percentage, but very large increase in the share of industry-services picking up the major share of the shift which is successively 27.12 and 51.70 in percentage.

\section{Phase 4. 2010 to 2012s:}

In this period (2010-2012), Structural changes continued at an accelerated pace where share of agriculture sharply declining and services emerging as the major sector with significant increase in the share of industry. Within this phase, 2010-2012 has seen a slowdown of agriculture and a sharp acceleration of services. The share of industry sector to GDP also considerably increases in the year of 2010 to 2012.

So it is seen that a faster structural shift from agriculture to non-agriculture and emergence of services as the dominant part of the economy. By examining a comparative data of sector wise GDP change of Bangladesh for the last 32 years (1980-2012), it is clear that from Table 1; 
On the Relationship between Economic Growth and CO2 Emissions: The Bangladesh Experience

Table 1: Lowest and Highest contribution (\% in value added) of Bangladesh

\begin{tabular}{|c|c|c|c|c|c|}
\hline \multirow{2}{*}{ Sectors } & \multirow{2}{*}{$\begin{array}{c}\text { Trends in GDP } \\
\text { Contribution }\end{array}$} & \multicolumn{2}{|c|}{$\begin{array}{c}\text { Lowest contribution } \\
\text { (year, \% in value added) }\end{array}$} & \multicolumn{2}{|c|}{$\begin{array}{c}\text { Highest contribution } \\
\text { (year, \% in value added) }\end{array}$} \\
\cline { 3 - 6 } & & Year & Value added & \multicolumn{2}{|c|}{ Year } \\
\hline Agriculture & Decreasing & 2012 & 17.68 & 1985 & 32.77 \\
\hline Industry & Increasing & 1980 & 20.63 & 2009 & 28.66 \\
\hline Services & Increasing & 1985 & 45.79 & 2012 & 53.86 \\
\hline
\end{tabular}

Source: World Development Indicators (2013), World Bank Data

The trends of $\mathrm{CO} 2$ emissions (metric tons per capita) regarding GDP per capita (current US\$) of Bangladesh from the year of 1972 to the year of 2010 graphically (Fig.5.1.2) shown in below;

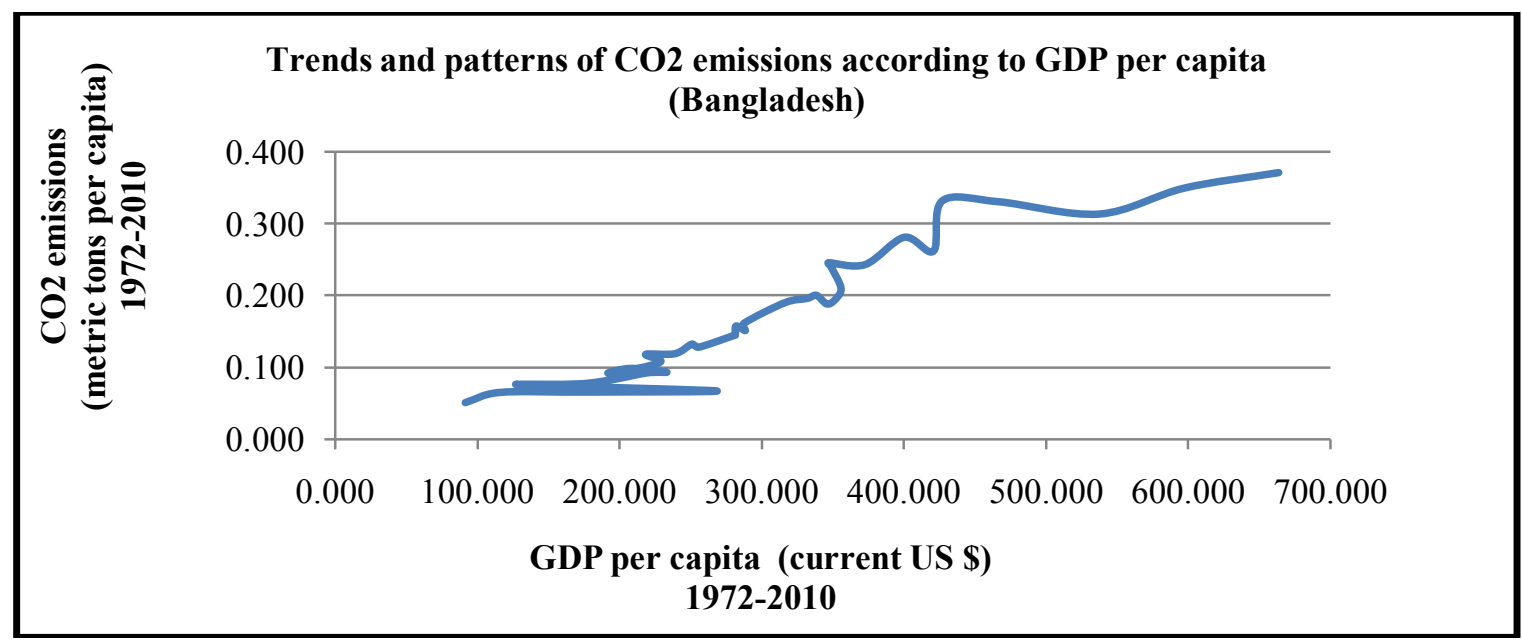

Source: World Development Indicators (2013), World Bank Data
Figure 5.1.2: Trends and patterns of CO2 emissions according to GDP per capita (Bangladesh)

The above graph of trends and patterns of $\mathrm{CO} 2$ emissions as regards of GDP per capita of Bangladesh (Fig.5.1.2) shows several turns and twists in $\mathrm{CO} 2$ emissions after Independence because several phases shows distinctive features of economic growth with structural changes. It is seen that $\mathrm{CO} 2$ emissions increase as GDP contribution of industry and services expansively rising. Manufacturing and industrial processes emit carbon dioxide directly through fossil fuel combustion as well services indirectly through the use of electricity that is generated using fossil fuels all combine to produce large amounts of each type of greenhouse gas but specifically large amounts of $\mathrm{CO} 2$.

\section{Findings}

By examining sector wise GDP change over the decade and year of Bangladesh it is clear that, the country is not capable to reduce $\mathrm{CO} 2$ emissions because GDP contribution of the industry and services sector extensively increases. For this reason we also unable to prove the existence of EKC shape (inverted-U shape) by estimating the period of 1972 to 2010. As CO2 is global pollutant not local pollutant and effects are not restricted by country boundaries so global cooperation are needed to reduce $\mathrm{CO} 2$ emissions.

\section{Conclusion}

The explanation based on structural changes; reveal us that environmental awareness, environmental policy, global cooperation, improved and polluting abatement technologies are needed in order to direct the environment-growth relationship toward a downward trend. Like Bangladesh, Developing countries should take better technical personnel and wider budgets for monitoring and enforcement activities to implement environmental policy. As stated by Panayotou (1993) "At higher levels of development, structural change towards information-intensive industries and services, coupled with increased environmental awareness, enforcement of environmental regulations, better technologies and higher environmental expenditures, result in leveling off and gradual decline of environmental degradation".

\section{References}

[1] Yandle B, Vijayaraghavan M, Bhattarai M 2002. The Environmental Kuznets Curve: A Primer. PERC Research Study 02-1.

[2] Panayotou T. 1993. Empirical test and policy analysis of environmental degradation at different stages of economic development, WP 238. Technology and Employement Program. International labour office. Geneva.

[3] Akbostancı E., S. Türüt-Asık and G. Đpek-Tunç 2009. The relationship between income and environment in Turkey: Is there an environmental Kuznets curve? Energy Policy 37, 861-867. 
[4] Cole, M.A., A.J. Rayner and J.M. Bates 1997. The environmental Kuznets Curve: and empirical analysis, Environmental and Development Economics 2, 401-416.

[5] Galeotti M., M. Manera and A. Lanza 2009. On the Robustness of Robustness Checks of the Environmental Kuznets curve Hypothesis, Environmental and Resource Economics 42, 551-574.

[6] Grossman M.G. and Krueger A.B. 1993. Environmental Impacts of a North American Free Trade Agreement. In Garber P. (ed.), The U.S.-Mexico Free Trade Agreement, 165.177. MIT Press, Cambridge, MA.

- 1995. Economic Growth and the Environment. Quarterly Journal of Economics, 60, 353.377.

[7] Maddison D., Rehdanz K. (2008), Carbon Emissions and Economic Growth: Causality Testing in Heterogeneous Panels, Globalization, Energy and Environment, Warsaw School of Economics, 29-30 May, 2008

[8] Miah Md. Danesh, Masum Md. Farhad Hossain, and Koike Masao, (2010), Global observation of EKC hypothesis for CO2, SOx and NOx emission: A policy understanding for climate change mitigation in Bangladesh, Energy Policy, 38, 4643-4651.

[9] Selden T. and Song D. 1994. Environmental Quality and Development: Is there a Kuznets Curve for Air Pollution Emissions? Journal of Environmental Economics and Management, 27, 147-162.

\section{Appendix}

\begin{tabular}{|c|c|c|c|}
\hline \multicolumn{5}{|c|}{ Sector Wise GDP change in percentage (Bangladesh) } \\
\hline Year & Agriculture & Industry & Services \\
\hline $1980-1989$ & 31.595 & 21.165 & 47.231 \\
\hline $1990-1999$ & 27.135 & 23.938 & 48.928 \\
\hline $2000-2009$ & 21.187 & 27.118 & 51.695 \\
\hline $2010-2012$ & 18.184 & 28.375 & 53.442 \\
\hline
\end{tabular}

\begin{tabular}{|c|c|c|}
\hline \multicolumn{3}{|c|}{ Trends and patterns of $\mathrm{CO} 2$ emissions according to GDP per capita (Bangladesh) } \\
\hline Year & GDP per capita (current US\$) & $\mathrm{CO} 2$ emissions (metric tons per capita) \\
\hline 1972 & 91.492 & 0.051 \\
\hline 1973 & 115.655 & 0.065 \\
\hline 1974 & 175.772 & 0.066 \\
\hline 1975 & 268.399 & 0.067 \\
\hline 1976 & 136.361 & 0.075 \\
\hline 1977 & 126.943 & 0.077 \\
\hline 1978 & 170.479 & 0.077 \\
\hline 1979 & 194.238 & 0.083 \\
\hline 1980 & 219.576 & 0.093 \\
\hline 1981 & 233.152 & 0.094 \\
\hline 1982 & 207.752 & 0.099 \\
\hline 1983 & 191.900 & 0.092 \\
\hline 1984 & 214.262 & 0.099 \\
\hline 1985 & 229.226 & 0.109 \\
\hline 1986 & 218.481 & 0.118 \\
\hline 1987 & 239.064 & 0.119 \\
\hline 1988 & 251.032 & 0.133 \\
\hline 1989 & 256.016 & 0.128 \\
\hline 1990 & 280.566 & 0.145 \\
\hline 1991 & 281.599 & 0.145 \\
\hline 1992 & 282.030 & 0.158 \\
\hline 1993 & 288.662 & 0.152 \\
\hline 1994 & 287.712 & 0.162 \\
\hline 1995 & 316.509 & 0.190 \\
\hline 1996 & 332.236 & 0.196 \\
\hline 1997 & 338.699 & 0.201 \\
\hline 1998 & 345.876 & 0.189 \\
\hline 1999 & 351.583 & 0.194 \\
\hline 2000 & 355.973 & 0.211 \\
\hline 2001 & 348.757 & 0.241 \\
\hline 2002 & 347.219 & 0.246 \\
\hline 2003 & 372.981 & 0.243 \\
\hline 2004 & 400.472 & 0.281 \\
\hline 2005 & 421.123 & 0.262 \\
\hline 2006 & 427.291 & 0.332 \\
\hline 2007 & 467.136 & 0.331 \\
\hline 2008 & 537.638 & 0.314 \\
\hline 2009 & 597.691 & 0.350 \\
\hline 2010 & 664.085 & 0.372 \\
\hline
\end{tabular}

